\title{
Book Review of Disrupting the Status Quo of Senior Living: A Mindshift by Jill Vitale-Aussem
}

\author{
Reviewed by Martha J. Giles, PhD \\ Walden University, Minneapolis, Minnesota, United States
}

Contact: martha.giles@mail.waldenu.edu

Date Submitted: December 19, 2019 | Date Published: February 5, 2020

Recommended Citation

Giles, M. J. (2020). Book review of Disrupting the status quo of senior living: A mindshift by Jill Vitale-Aussem. Journal of Social, Behavioral, and Health Sciences, 14, 1-2. https://doi.org/10.5590/JSBHS.2020.14.1.01

\section{Introduction}

Disrupting the Status Quo of Senior Living: A Mindshift by Jill Vitale-Aussem, Health Professions Press, 2019, ISBN 978-1938870828, 216 pages.

Jill Vitale-Aussem's 2019 book Disrupting the Status Quo of Senior Living: A Mindshift is organized around introducing new perspectives regarding senior living communities. The author based the book on her experiences working within senior communities according to three models: health care, hospitality, and community building. She introduces traditional ways of working with adults in these communities (health care and hospitality) in Chapters 1-4. She also discusses how these traditional approaches may not be the most beneficial for either the workers or the residents. In Chapters $5^{-11}$, she suggests new approaches and methods for enhancing the life experience for residents and staff, including suggestions for changing existing models. She discusses many issues facing adults as they move into senior communities including technology, friendships, food service, autonomy, and safety, to name a few. Each chapter is followed up by "Questions for Discussion and Introspection.”

This book is informative and introduces the reader to subtle and obvious agism and ableism within senior living communities. The author uses humor to engage the reader in examining his or her own possible ageist and ableist beliefs. It is well written, though not in a scholarly sense. It is based more upon Vitale-Aussem's own experiences through 20+ years of nursing home and assisted living administration. Vitale-Aussem uses footnotes throughout that support her beliefs and experience, though they are often not scholarly sources. It seems more of a personal examination of ways in which professionals may approach a senior community and the benefits and drawbacks of those specific approaches.

A strength of this book is the clear messages about ageism and ableism that Vitale-Aussem draws from her own experience and asks the readers to draw from theirs. She also gives examples of the benefits of a true community with all individuals playing specific roles. She fills the book with stories from her life and from those with whom she has worked.

Note: Dr. Giles is the research coordinator for Walden University's College of Social and Behavioral Sciences. She has published on differing aspects of aging. She is a licensed psychologist and has taught in the School of Psychology at Walden for over 15 years. 
A drawback is the lack of scholarly inquiry into best practices within these communities and the potential societal strengths of developing these practices. With more senior living communities being established in this country, a clear understanding of best practices in working in those communities is necessary. However, the book is a great introduction to the world of senior communities and what can be done to allow adults to age while maintaining their independence, sharing learned wisdom, and developing a sense of belonging. A more scholarly approach would allow readers to learn best practices but would not give them the opportunity to experience senior living the way Vitale-Aussem presents it. An understanding of our own ageist beliefs and biases should be a requirement for anyone working in social or behavioral health sciences. In that respect, this is an excellent introductory text for college students who may go on to study aging populations.

I enjoyed this book and would recommend it to anyone interested in working with or studying differing aspects of aging. The most significant aspect of this book, for me, was the author's imploring the reader to examine his or her own agism and ableism.

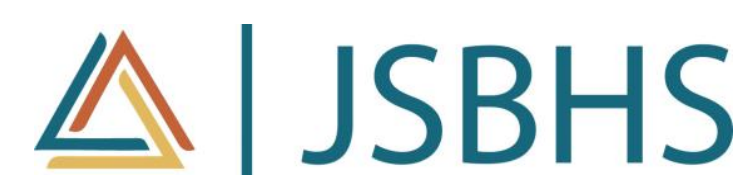

The Journal of Social, Behavioral, and Health Sciences (JSBHS), co-sponsored by the College of Health Sciences and the College of Social and Behavioral Sciences at Walden University, is a peer-reviewed, online, interdisciplinary journal focusing on theoretically-based research that addresses contemporary national and international issues. JSBHS articles include peer-reviewed research reports, brief resports, comprehensive literature reviews, books reviews, and student research. 